\title{
Modeling of the Potential Honey Bee Colony Foraging Activity Based on the Agrometeorological Factors
}

\author{
Olvija KOMASILOVA, Vitalijs KOMASILOVS, Armands KVIESIS, \\ Aleksejs ZACEPINS
}

Department of Computer Systems, Faculty of Information Technologies, Latvia University of Life Sciences and Technologies, Liela iela 2, Jelgava, LV-3001, Latvia

olvija.komasilova@llu.lv, vitalijs.komasilovs@llu.lv, armands.kviesis@llu.lv, aleksejs.zacepins@llu.lv

\begin{abstract}
Honey bees are the main pollinators of the most agricultural plants on our planet. Foraging behaviour is one of the distinctive behaviours of honey bees and is like a link between the honey bee colony and the ambient environment. It is well known that environmental and meteorological factors can have either positive or negative impact on the foraging activity and the amount of gathered nectar and honey production. This research summarises the effect of the main agrometeorological factors, like temperature, humidity, wind and intensity of precipitation on the foraging activity. Within this research, a model for potential honey bee colony foraging activity based on the agrometeorological factors is presented and described. For the calculations weather forecast is used, either by the manual input or by the automatic uploading using the JSON format. The outcome of the model allows the beekeepers to predict and evaluate the potential amount of nectar to be foraged during the active season or specific period of time. This research is conducted within the Horizon 2020 FET programme project HIVEOPOLIS (https://www.hiveopolis.eu/).
\end{abstract}

Keywords: Precision Beekeeping, bee colony foraging, foraging optimisation, agrometeorology, smart beekeeping, Hiveopolis

\section{Introduction}

One of the main outcomes of beekeeping for the beekeepers is the amount of honey bee colonies can produce. Honey production and bee colony foraging activity is dependent on various factors like colony strength (Amdam et al., 2009), colony development stage, rate of colony infection (Kralj and Fuchs, 2010), environmental conditions, insecticides (Yang et al., 2008), availability of foraging resources (Abou-Shaara, 2014) and others. Additionally, honey bees provide essential pollination services for wild flowers and crops, worth billions of US\$ (Breeze et al., 2016; Potts et al., 2016).

This research tries to numerically evaluate the effect of agrometeorological factors on the bee colony foraging activity and lies within the precision beekeeping direction, which is defined by Zacepins et al. (2015) and characterised by the remote colony monitoring to maximise its productivity. The developed model helps the beekeepers to 
estimate the potential amount of honey that can be foraged in the target location taking into consideration agrometeorological factors. Having this data for different locations, beekeepers can decide on better apiary locations. Previously authors developed a model for the bee apiary location evaluation (Komasilovs et al., 2020), which can be used by the beekeepers to choose the suitable place for the apiary, taking into account surrounded fields and flowering activity, and location itself, but meteorological factors were not considered. Agrometeorology is the study of weather and use of weather and climate information to enhance or expand agricultural crops and/or to increase crop production (Frere, 1979).

Agrometeorological factors determine the bee colony viability and productivity rates of the nectar plants. Agrometeorological factors include: temperature, humidity, wind, precipitation, solar radiation and etc. (Hoogenboom, 2000).

The importance of the influence of meteorological elements on honey bee flight activity and plant nectar excretion is well recognized and shows that bee species are affected by weather conditions in various ways (Clarke and Robert, 2018). Significant influence of air temperature, humidity, precipitation, minimum and maximum air temperature, as well as wind strength was observed by researchers (Puškadija et al., 2007). The weather conditionals all influence what a worker bee will do at any time moment in the colony (Page and Robinson, 1991).

Bee colony productivity is closely connected to the plant nectar excretion and this process is related to the environmental factors. Each plant can have different characteristics and levels of nectar and pollen production, as weather conditions can alter the quantity and sugar concentration of nectar in flowers (Corbet, 1990). The minimal temperature needed for the most plants to start producing nectar is $10^{\circ} \mathrm{C}$ and usually with the increase of the ambient temperature this process is intensifying. When temperature is between $16^{\circ} \mathrm{C}$ and $25^{\circ} \mathrm{C}$ the nectar excretion is the most active, but when temperature reaches $30-32^{\circ} \mathrm{C}$ this process practically ceases, excluding some south plants which can have nectar till $38^{\circ} \mathrm{C}$ (Bajazitova et al., 2016). Increasing temperatures enhance flight activity while decreasing temperatures have the inverse effect (Burrill and Dietz, 1981). From the bee colony side, bees would not fly at all if the ambient temperature did not exceed $9^{\circ} \mathrm{C}$ regardless of light intensity (Burrill and Dietz, 1981). Also beekeepers approve by the visual inspections that bees are not flying if the ambient temperature is less than $8^{\circ} \mathrm{C}$. Honey bee A.mellifera is fully active at temperatures higher than $12-14^{\circ} \mathrm{C}$ and solar radiation higher than $300 \mathrm{w} / \mathrm{m} 2$ (Heinrich, 2013). At ambient temperatures of about $20^{\circ} \mathrm{C}$, the highest activity was recorded (Tan et al. 2012) while at $43^{\circ} \mathrm{C}$ the lowest foraging activity was observed (Blazyte-Cereskiene et al. 2010).

Also humidity has an effect on the nectar excretion, it is observed that the plants are mostly active at humidity level 60-80 \% (Pankov, 2008).

(Kumar et al., 2002) pointed out agro-ecological data for Punjab county in India showing the most intensive bee activity at $18.3^{\circ} \mathrm{C}$ and $60 \%$ humidity. (Miklič et al, 2002) presents data obtained at Rimski Šančevi site near Novi Sad, Serbia, and he observed the most intensive bee activity at $20-28^{\circ} \mathrm{C}$ and humidity at $40-50 \%$.

Optimal weather conditions for the massive nectar excretion can be described as warm, without wind, sunny weather with short rainfalls during the night and relatively high humidity. Such weather conditions also support a high flight activity of the bee colony. 
Based on several scientific researches, rain not only disturbs the bee flights but also can wash away the nectar from the flowers (Vorobjeva, 2015; Gaeva, 2015), thus having strong negative impact on honey bee activity and pollination. Huge precipitations may also lead to the death of faragers if they are not able to reach the hive on time.

It is observed that wind is the only meteorological factor which has no positive effect on the nectar excretion. Strong and especially dry wind has a negative effect on the honey plant development process (Gaeva, 2008).

Natural environments are characterized by variable wind that can pose significant challenges for flying animals and insects (Crall et al., 2017). Wind variability represents one of the most important, and potentially most challenging, components of environmental complexity for flying animals. It is not well described how the find affects the flight activity and there appear to be no data directly measuring the effect of wind speed on the foraging rates of individual bees (Hennessy et al., 2020), but it is clear that strong wind prevents bees from active flying, or bees have to spend more energy for the foraging and flying processes. Despite being subjected to a wide range of speeds and turbulence intensities, some authors found that bees do not avoid foraging in windy conditions (Crall et al., 2017). (Vicens and Bosch, 2000) identified that wind speed is a major environmental factor influencing the number of foraging honey bees on apple trees.

In addition also atmospheric pressure can affect the flight frequencies of the bee colonies. As well it should be mentioned, that bees will not fly if there is no light. Within the meteorological factors temperature and solar radiation appeared to be the major factors influencing honey bee flight initiation.

Aim of this publication is to present a model for honey bee colony foraging activity based on the agrometeorological factors. Outcome of the model allows the beekeepers to predict and evaluate the potential amount of nectar to be foraged and honey gain by the colony during the active season or specific period of time.

This research is conducted within the Horizon 2020 FET programme project HIVEOPOLIS (https://www.hiveopolis.eu/).

\section{Overall model description}

The model presented here helps to evaluate the overall honey production from the nectar foraging and its losses due to the agrometeorological factors. It is a prediction model which uses the weather forecast as input. It can use short-term or long-term (up to a couple of weeks) weather forecasts provided by the online services. As an additional option for the modeling process, meteorological data sets from previous years can be used under the assumption that future weather will be similar to the long-term average for the specific geographical location.

There are some prerequisites for the model operation. Users have to know and input honey foraging period (by months) in the target location and the average foraging activity (in percents) in that period. The total number of percent should be $100 \%$ for the whole period. In some regions where foraging is equal in all months, foraging activity per month would be $100 / 12=8.33 \%$.

Another input parameter required by the model is the amount of nectar that potentially can be foraged by the strong colony per day in a good weather condition. 
Then taking into account the monthly coefficients it is possible to calculate the average amount of honey for each day.

All this information should be prepared prior to the prediction and adjustment phase. When it is completed, then the model can adjust values based on the weather forecast using previously defined model parameters (described in the next section "Model and parameterisation"). Weather data can be inputted manually or uploaded using the JSON (JavaScript Object Notation) format.

The model has been developed and tested in a Python environment, but in the future it is planned to create a user interface for a more attractive visual representation.

\subsection{Model and parameterisation}

Below all model equations are presented and shortly explained.

The "Overall bee colony foraging coefficient" (OFC) is dependent on all individual weather coefficients and thus is multiplication of them, resulting in formula below:

OFC $=$ Coef $_{\text {Temperature }} * \operatorname{Coef}_{\text {Humidity }} * \operatorname{Coef}_{\text {Wind }} * \operatorname{Coef}_{\text {Rain }}$, where:

Coef $_{\text {Temperature }}$ - foraging coefficient which is calculated based on ambient temperature values,

Coef $f_{\text {Humidity }}$ - foraging coefficient which is calculated based on ambient humidity values,

Coef $f_{\text {Wind }}$ - foraging coefficient which is calculated based on ambient wind values,

Coef $f_{\text {Rain }}$ - foraging coefficient which is calculated based on the amount of precipitation.

For the calculation of the average amount of honey gain for each day of the month equation below is used:

Honey foraging per day [i] $=$ Honey $_{\text {day }} *$ Days $_{\text {active }} *$ Coeff $_{\text {month }[i]} /$ Days in the month $[i]$, where

Honey $_{\text {day }}$ - assumed amount of honey foraged per day by the strong colony in good weather conditions.

Days $_{\text {active }}$ - overall number of days, when foraging can happen

Coeff month $[i]$ - honey foraging intensity coefficient for specific month

Days in the month $[i]$ is equal to the number of days in corresponding month.

For the calculation of the amount of honey gain for each day of the active foraging period equation below is used:

Amount of honey per day $[\mathrm{i}]=$ Honey foraging per day $[i] * \mathrm{OFC}$

And for calculation of the amount of honey gain for the whole period equation below is used:

Amount of honey per period $=\sum$ Amount of honey per day[i]

\subsection{Parameters}

Analysing the available sources and literature, the authors defined agrometeorological parameters and its values for the Latvian case. It was decided to use four main parameters: temperature, humidity, wind and precipitation. Parameter values can be changed and adapted for other regions or bee species. Values are presented in a form of rules. 


\section{Temperature}

Foraging coefficient which is calculated based on average ambient temperature values for any potential time period is called Coef $_{\text {Temperature }}$ and is calculated as follows:

If temperature is $<8^{\circ} \mathrm{C}$ or $>35^{\circ} \mathrm{C}$ then $\mathrm{Coef}_{\text {Temperature }}$ is 0

If temperature is between $8^{\circ} \mathrm{C}$ and $14^{\circ} \mathrm{C}$ then Coef $_{\text {Temperature }}$ is 0.1

If temperature is between $15^{\circ} \mathrm{C}$ and $19^{\circ} \mathrm{C}$ then Coef $_{\text {Temperature }}$ is 0.8

If temperature is between $20^{\circ} \mathrm{C}$ and $30^{\circ} \mathrm{C}$ then Coef $_{\text {Temperature }}$ is maximal and is 1

If temperature is between $31^{\circ} \mathrm{C}$ and $35^{\circ} \mathrm{C}$ then Coef $_{\text {Temperature }}$ is 0.2

Humidity

Foraging coefficient which is calculated based on ambient humidity values is called Coef $_{\text {Humidity }}$ and is calculated as follows:

If humidity is between $60 \%$ and $80 \%$ then Coef $_{\text {Humidity }}$ is maximal and is 1

If humidity is $<50 \%$ or $>90 \%$ then Coef $_{\text {Humidity is }} 0.8$

If humidity is between $50 \%$ and $60 \%$ or between $80 \%$ and $90 \%$ then Coef Humidity $_{\text {is }}$

0.9

Wind

Foraging coefficient which is calculated based on ambient wind values is called Coef $_{\text {Wind }}$ and is calculated as follows:

If wind speed is $<=5 \mathrm{~m} / \mathrm{s}$ then Coef $_{\text {Wind }}$ is maximal and is 1

If wind speed is between $5 \mathrm{~m} / \mathrm{s}$ and $20 \mathrm{~m} / \mathrm{s}$ then Coef $_{\text {Wind }}$ is calculated by the

following formula: $(100$ - wind speed value $* 5) / 100$

If wind speed is $>20 \mathrm{~m} / \mathrm{s}$ the Coef $_{\text {Wind }}$ is 0

Precipitation (Rain)

Foraging coefficient which is calculated based on the amount of precipitation is called Coef $_{\text {Rain }}$ and is calculated by the formula: $(100$ - Rain probability $(\%)) / 100$. It results in values from 0 to 1 and meaning if $\operatorname{Coef}_{\text {Rain }}$ is equal to 0 , then it is $100 \%$ probability of the rain and bees will not fly from the hive.

\section{Example of model calculations}

Within this section example calculations using the model are presented for the local case for Latvia. In Latvia, the active foraging period is usually from early April till end of August, but the nectar foraging intensity coefficients are different for different months. To get the monthly coefficients authors summarised bee foraging activity during the six years at one apiary, located in Dobele region. Data is used from the public web system: http://svari.strops.lv/\#/. To get the coefficients, summarised weight gains during the one month are divided by the overall weight gain for the observed period (see Table 1). Unfortunately, the coefficients can be dependent on the specific location and seasonal forage availability. So for the best model performance those coefficients should be calculated for specific apiary location.

Rounded coefficients are presented below for the whole year (January-December): $[0,0,0,0.06,0.29,0.36,0.22,0.07,0,0,0,0]$ and are called Coef MonthAbbreviation. $_{\text {. }}$. 
For instance $\operatorname{Coef}_{\text {Apr }}=0.06$ or $6 \%$. This coefficient is inputted by the user, based on overall knowledge of bee foraging periods and overall bee activity in the target region.

Next parameter needed for the model is the amount of honey gain per day by a strong colony in good weather conditions. It is assumed that the colony can gain $1.5 \mathrm{~kg}$ of honey (variable Honey $_{\text {day }}$ ). It is necessary to emphasize that this amount used by the authors is already excluding the honey consumed by the colony itself, but it is also possible to use the overall foraged amount of nectar by the colony.

Table 1. Overview of the bee colony weight gain proportion during the several years in one location in Dobele region, Latvia

\begin{tabular}{|l|c|c|c|c|c|c|r|}
\hline & \multicolumn{1}{|c|}{2015} & 2016 & 2017 & 2018 & 2019 & \multicolumn{1}{c|}{2020} & Average \\
\hline April & $0.30 \%$ & $5.87 \%$ & $1.38 \%$ & $3.25 \%$ & $16.42 \%$ & $8.06 \%$ & $5.88 \%$ \\
\hline May & $12.98 \%$ & $21.98 \%$ & $35.58 \%$ & $42.39 \%$ & $38.61 \%$ & $24.52 \%$ & $29.34 \%$ \\
\hline June & $15.94 \%$ & $52.52 \%$ & $43.01 \%$ & $28.80 \%$ & $33.73 \%$ & $40.11 \%$ & $35.69 \%$ \\
\hline July & $63.63 \%$ & $18.12 \%$ & $9.84 \%$ & $16.15 \%$ & $3.11 \%$ & $21.72 \%$ & $22.10 \%$ \\
\hline August & $7.15 \%$ & $1.51 \%$ & $10.19 \%$ & $9.40 \%$ & $8.14 \%$ & $5.60 \%$ & $7.00 \%$ \\
\hline
\end{tabular}

Then it is possible to calculate the overall honey that potentially can be gained during the whole active period (April - August, 153 days) in a perfect weather conditions:

$1.5 \mathrm{~kg} * 153$ days (variable Days active $)=229.5 \mathrm{~kg}$ of honey $\left(\right.$ variable Honey $\left._{\text {all }}\right)$.

Taking into account the monthly coefficients it is possible to calculate the average amount of honey gain for each day of the month (Honey foraging per day [i]).

Example for April could be:

DayHoney $_{\text {Apr }}=1.5 * 153 * 0.06 / 30=0.46 \mathrm{~kg}$

In a result we will get such an outcome for each month:

$[0.0,0.0,0.0,0.46,2.15,2.75,1.63,0.52,0.0,0.0,0.0,0.0]$

Now we can use the agrometeorological factors and its values to adjust and predict the potential honey gain for the whole active foraging period.

\subsection{Scenario Nr.1 - Random values for the demonstration}

For the random value generation several rules and value limits were used. Below used values are presented:

Average minimum and maximum temperature for each month based on the : tempMinYearMonth $=[-20,-10,0,5,15,15,15,10,0,-5,-15,-20]$

tempMaxYearMonth $=[5,5,10,20,30,30,30,30,15,10,10,5]$,

Where tempMinYearMonth[i] - represents possible minimum value for the specific month during the daylight time and tempMaxYearMonth[i] represents possible maximum value for the specific month during the daylight time.

Humidity: from 30 to $100 \%$

Wind speed: from 0 to $20 \mathrm{~m} / \mathrm{s}$ 
Rain probability: from 0 to $100 \%$

Then all random values are generated using the Python function for random number generation for the whole active foraging period (in this case from April to August).

Generated random values are presented in the weather_data_random.csv file (supplementary materials).

To demonstrate the calculation process let's take values for the 1 of April (DayHoney[1 of April $]=0.46$, Temperature $=16^{\circ} \mathrm{C}$, Humidity $=47 \%$, Wind $=3 \mathrm{~m} / \mathrm{s}$ and Rain $=19 \%$ ), then

Amount of honey per day [ 1 of April] $=0.46 * 0.8 * 0.8 * 1 * 0.81=0.24 \mathrm{~kg}$

Using the provided data overall honey gain per whole active period is equal to $50.18 \mathrm{~kg}$. This number may not correspond to the real situation, as it was mentioned before, agrometeorological factors were defined using the random number approach.

\subsection{Scenario Nr.2 - Using the json file for data input}

Developed model allows uploading data using the JSON (JavaScript Object Notation) format. For example, user uploads such a JSON file:

\{

"date": "2020-05-10",

"temp_avg_c": 23,

"humidity": 38 ,

"wind_mps": 3.2

"rain_per": 0,

\}

Then using those values the model will calculate the potential amount of honey gain for this day.

Users are not limited to just one day using JSON, but can also input data for a long period.

Honey $[10$ of May $]=2.15 * 1 * 0.8 * 1 * 1=1.72 \mathrm{~kg}$

\subsection{Scenario Nr.3 - Using the actual weather forecast for modeling}

This scenario demonstrated the ability of the model to use the real-time weather forecast for the honey gain prediction, using the previously mentioned feature to use the JSON format input data.

As a source for the meteorological factors data from the online service https://openweathermap.org/ was used. Using this service it is possible to obtain data for 3 hour intervals for the period of five days based on geographical coordinates. Authors assumed that honey bee foraging activity during the day can be splitted into six intervals for each 3 hours starting from 6:00 to 21:00. It means that DayHoney [i] coefficients should be divided by 6 . Additionally within this data from the mentioned weather forecast service there is no clear data about the amount of precipitation, but there is a weather type defined based on the amount of precipitation. And it is concluded that if the weather type is less than 700, the weather is not suitable for flying and foraging and it is 
assumed that $\operatorname{Coef}_{\text {Rain }}=0$. But the calculations afterwards are the same, as already described previously. Weather coefficients are multiplied with hourly honey amounts on specific days.

\subsection{Validation of the developed model}

At this stage the developed model is only theoretical and in the future it should be validated in the real environment by practical experiments. But already now it could be used by the beekeepers to predict the bee colony foraging activity and its deviation based on the short-term or even long-term weather forecast.

To validate the model authors used publicly available data for one bee colony weight changes during one active foraging period. Data is used from http://svari.strops.lv/\#/ Historical weather data is used from the publicly available meteorological service www.meteo.lv. Nearest meteo station to the target apiary location was found. Data from the meteo station about the meteorological parameters can be found in the supplementary materials (weather_Dobele_2018.csv).

Using the bee colony weight data it is found that during the active foraging period weight was increased by $108.2 \mathrm{~kg}$ in total. Using the developed model the achieved predicted result is $118.49 \mathrm{~kg}$. The model showed a deviation of $9 \%$ from the real value.

In the future it is planned to have a comprehensive practical experiment where bee colony weight changes and weather will be jointly fixed to further adapt the developed model.

\section{Conclusions}

One of the aims of the precision beekeeping is to maximize the bee colony honey production and the developed model can help the beekeepers to estimate the potential amount of honey that can be gained in the target location. Knowing the agrometeorological factors for different locations, beekeeper can decide on a better apiary location.

The importance of the foraging activity is generally well recognised, but the impact of the environmental factors is still not clearly known.

As it can be seen from this research, good apiary location cannot guarantee high foraging, as weather conditions can introduce some significant deviations.

Authors presented the developed model for the potential honey bee colony foraging activity based on the agrometeorological factors. There are four main agrometeorological factors considered in the model: temperature, humidity, wind and amount of precipitation. In the future it is planned to include other factors, like solar radiation, wind direction and air pressure.

At this moment the model is developed in the Python language without interactive user interface, but in the future it is planned to develop a separate web interface to ease the interaction with the model for the end users.

Defined model parameters are based on the literature review but in case of need can be adapted and changed for the target regions and locations. 


\section{Acknowledgment}

This work was supported by the project HIVEOPOLIS which has received funding from the European Union's Horizon 2020 research and innovation programmes under grant agreement No. 824069.

The authors would like to thank Mathias Becker from University of Graz for his valuable review of the manuscript and suggestions on how to improve the publication.

\section{References}

Abou-Shaara, H.F. (2014). The foraging behaviour of honey bees, Apis mellifera: a review. Veterinarni Medicina, 59(1), 1-10

Amdam, G.V., Rueppell, O., Fondrk, M.K., Page, R.E., Nelson, C.M. (2009). The nurse's load: Early-life exposure to brood-rearing affects behavior and lifespan in honey bees (Apis mellifera). Experimental gerontology, 44(6-7), pp.467-471.

Bajazitova, K.N., Takenova, D.E., Amelina, V.A., Konkarova, M.B. (2016). Agrometeorological factors affecting the vital activity of bees in the conditions of Northern Kazakhstan (Russian). In proceedings of IV international scientific conference "Actual problems of science and education in the field of natural and agricultural sciences", 1, pp.27-30.

Blažytè-Čereškienè, L., Vaitkevičienè, G., Venskutonytė, S., Būda, V. (2010). Honey bee foraging in spring oilseed rape crops under high ambient temperature conditions. Žemdirb.(Agric.), 97, pp.61-70.

Breeze, T.D., Gallai, N., Garibaldi, L.A., Li, X.S. (2016). Economic measures of pollination services: shortcomings and future directions. Trends in Ecology \& Evolution, 31(12), pp.927-939. https://doi.org/10.1016/j.tree.2016.09.002

Burrill, R.M., Dietz, A. (1981). The response of honey bees to variations in solar radiation and temperature. Apidologie, 12(4), pp.319-328.

Clarke, D., Robert, D. (2018). Predictive modelling of honey bee foraging activity using local weather conditions. Apidologie, 49(3), pp.386-396.

Crall, J.D., Chang, J.J., Oppenheimer, R.L., Combes, S.A. (2017). Foraging in an unsteady world: bumblebee flight performance in field-realistic turbulence. Interface Focus, 7(1), p.2016.0086. https://doi.org/10.1098/rsfs.2016.0086

Corbet, S.A. (1990) Pollination and the weather Israël J. Bot. 39, 13-30. https://doi.org/10.1080/0021213X.1990.10677131

Frere, M. (1979). Overview of Agrometeorology. In ESA Special Publication (Vol. 1020, p. 3).

Gaeva, D.V. (2008). Influence of abnormal environmental conditions on the viability of bees (Russian). Bulletin of the Baltic Federal University of I. Kant. Series: Natural and Medical Sciences (1), pp.62-65.

Gaeva, D.V. (2015). Geoecological aspects of beekeeping optimization in the system of agricultural nature management in the Kaliningrad region (Doctoral dissertation, Russian).

Heinrich, B. (2013). The hot-blooded insects: strategies and mechanisms of thermoregulation. Springer Science \& Business Media.

Hennessy, G., Harris, C., Eaton, C., Wright, P., Jackson, E., Goulson, D., Ratnieks, F.F. (2020). Gone with the wind: effects of wind on honey bee visit rate and foraging behaviour. Animal Behaviour, 161, pp.23-31.

Hoogenboom, G. (2000). Contribution of agrometeorology to the simulation of crop production and its applications. Agricultural and forest meteorology, 103(1-2), pp.137-157.

Komasilovs, V., Bumanis, N., Zacepins, A., Mellmann, H., Komasilova, O., Kviesis, A. (2020). Model for the bee apiary location evaluation. Agronomy Research 18(S2), 1350-1358. 
Kralj, J., Fuchs, S. (2010). Nosema sp. influences flight behavior of infected honey bee (Apis mellifera) foragers. Apidologie, 41(1), pp.21-28.

Kumar, M., Singh, R., Chand, H. (2002). Foraging activity of Apis cerana indica and Apis mellifera visiting sunflower (Helianthus annuus L.). Shashpa, 9(1), pp.31-34.

Miklič V., Dušanić N., Atlagić J., Sakač Z., Joksimović J., Crnobarac J., Mihailović D., Vasić D. (2002). Influence of genotype, fertilization and microclimate on pollinator visit and sunflower yield (Bosnian). Proceedings of the Institute of Field and Vegetable Crops, 36, pp.179-188.

Pankov, D.M. (2008). Dependence of pollination of honey plants on weather conditions (Russian). Actual problems of science and education, 6, pp.75-79.

Puškadija, Z., Štefanić, E., Mijić, A., Zdunić, Z., Parađiković, N., Florijančić, T., Opačak, A. (2007). Influence of weather conditions on honey bee visits (Apis mellifera carnica) during sunflower (Helianthus annuus L.) blooming period. Poljoprivreda, 13(1), pp.230-233.

Page, R.E., Robinson, G.E. (1991). The genetics of division of labour in honey bee colonies. In Advances in insect physiology (Vol. 23, pp. 117-169). Academic Press.

Potts, S.G., Imperatriz-Fonseca, V., Ngo, H.T., Aizen, M.A., Biesmeijer, J.C., Breeze, T.D., Dicks, L.V., Garibaldi, L.A., Hill, R., Settele, J., Vanbergen, A.J. (2016). Safeguarding pollinators and their values to human well-being. Nature, 540(7632), pp.220-229. https://doi:10.1038/nature20588

Tan, K., Yang, S., Wang, Z.W., Radloff, S.E., Oldroyd, B.P. (2012). Differences in foraging and broodnest temperature in the honey bees Apis cerana and A. mellifera. Apidologie, 43(6), pp.618-623.

Vicens, N., Bosch, J. (2000). Weather-dependent pollinator activity in an apple orchard, with special reference to Osmia cornuta and Apis mellifera (Hymenoptera: Megachilidae and Apidae). Environmental entomology, 29(3), pp.413-420.

Vorobjeva, S.L. (2015). The influence of abiotic factors on the productivity of bees in the conditions of the Udmurt Republic (Russian). Modern problems of science and education, (1-1), pp.1672-1672.

Yang, E.C., Chuang, Y.C., Chen, Y.L., Chang, L.H. (2008). Abnormal foraging behavior induced by sublethal dosage of imidacloprid in the honey bee (Hymenoptera: Apidae). Journal of Economic Entomology 101, 1743-1748.

Zacepins, A., Brusbardis, V., Meitalovs, J., Stalidzans, E. (2015). Challenges in the development of Precision Beekeeping. Biosystems Engineering, 130, pp.60-71.

Received March 10, 2021, revised August 3, 2021, accepted August 11, 2021 